\title{
A STUDY OF POTASSIUM PERMANGANATE FIXATION FOR ELEGTRON MICROSGOPIC DETEGTION OF SMALL GRANULAR VESICLES IN THE SYMPATHETIC NERVOUS SYSTEM
}

\author{
Junzo OCHI \\ Department of Anatomy (Director: Prof. Y. SANO), Kyoto \\ Prefectural University of Medicine, Kyoto \\ Received for Publication February 1, 1969
}

\begin{abstract}
A $3 \%$ solution of potassium permanganate is effective at acid $\mathrm{pH}$ as a fixative for the small noradrenaline-containing granular vesicles of the symapthetic nervous system. The observed high electron density of the central granules in the vesicles is probably due to precipitated $\mathrm{MnO}_{2}$ which is reduced $\mathrm{KMnO}_{4}$ in a coupled oxidation of noradrenaline to noradrenochrome. A $3 \%$ solution of $\mathrm{KMnO}_{4}$ in dichromate buffer $(\mathrm{pH} 6.0)$ is particularly suitable for the fixation of the vesicles. This may be due to the additional precipitation of a chromic compound reduced from the dichromate.
\end{abstract}

Routine $\mathrm{OsO}_{4}$ fixation is not always suitable for electron microscopic detection of the small granular vesicles with a diameter of ca. $500 \AA$ in the symapthetic nervous system. These vesicles have central electron dense granules which are believed to contain noradrenaline $(3,11,6)$. Various attempts have been made by several investigators to preserve the central granules of the granular vesicles $(12,2,10,5$, 8).

The method of Richardson (10), Hökfelt (7) and Ochi et al.(9), potassium permanganate fixation $\left(3 \% \mathrm{KMnO}_{4}, \mathrm{pH} 7.0-7.3\right)$, has proved most suitable for the detection of vesicles, although the general fixation of the tissues was somewhat less than excellent. The aim of the present study is to examine the influence of the $\mathrm{pH}$ of the $\mathrm{KMnO}_{4}$ solution on the fixation of the granular vesicles and to determine the origin of the high electron density of the central granules in the vesicles. An attempt has also been made to improve the fixation quality of the tissues by use of a modified $\mathrm{KMnO}_{4}$ solution.

\section{MATERIALS AND METHODS}

Materials used were rabbit iris, normal and reserpinized $(5 \mathrm{mg} / \mathrm{kg}, 4-12 \mathrm{hr}$ before sacrifice), and rat brown adipose tissue. Rabbits were sacrificed under Nembutal anesthesia and rats with an occipital blow.

To determine the influence of the $\mathrm{pH}$ of $3 \% \mathrm{KMnO}_{4}$ solutions on the fixation of the granular vesicles, the following fixatives were prepared using different buffer systems covering a $\mathrm{pH}$ range from 1.0 to 10.0 ;

1) $3 \% \mathrm{KMnO}_{4}$ in $\mathrm{HCl}-\mathrm{KCl}$ buffer $(\mathrm{pH} 1.0)$

2) $3 \% \mathrm{KMnO}_{4}$ in phosphate buffer $(\mathrm{pH} 5.8,7.0$ and 7.9 )

3) $3 \% \mathrm{KMnO}_{4}$ in borax-NaOH buffer (pH 10.0). 
In addition, $3 \% \mathrm{KMnO}_{4}$ in $0.1 \mathrm{M}$ potassium dichromate- $\mathrm{KOH}$ buffer at $\mathrm{pH}$ 6.0-7.0 was also employed in the expectation that a reaction product of dichromate with noradrenalin would lead to increased electron density of the granules in the vesicles.

Small pieces of tissue were fixed for $2 \mathrm{hr}$ at $4^{\circ} \mathrm{G}$, then dehydrated in a graded series of acetones, and routinely embedded in Epon 812. Ultrathin sections were cut with a Porter-Blum MT-1 ultramicrotome and examined in a JEM-7 electron microscope, either without staining or after light staining with uranyl acetate to enhance background contrast.

Some unstained sections mounted on platinum grids were treated with fuming hydrochloric, nitric and sulfuric acids or conc. sodium hydroxide for $5 \mathrm{~min}$ after electron microscopic pre-examination, and immediately after that re-examined, especially with regard to changes of the granular vesicles in the identical areas which had been pre-examined.

\section{RESULTS}

\section{The validity of $\mathrm{KMnO}_{4}$ fixation for the granular vesicles.}

Two apposed, fine unmyelinated axons, one with a number of small granular vesicles and the other with agranular vesicles, covered by the cytoplasm of a Schwann
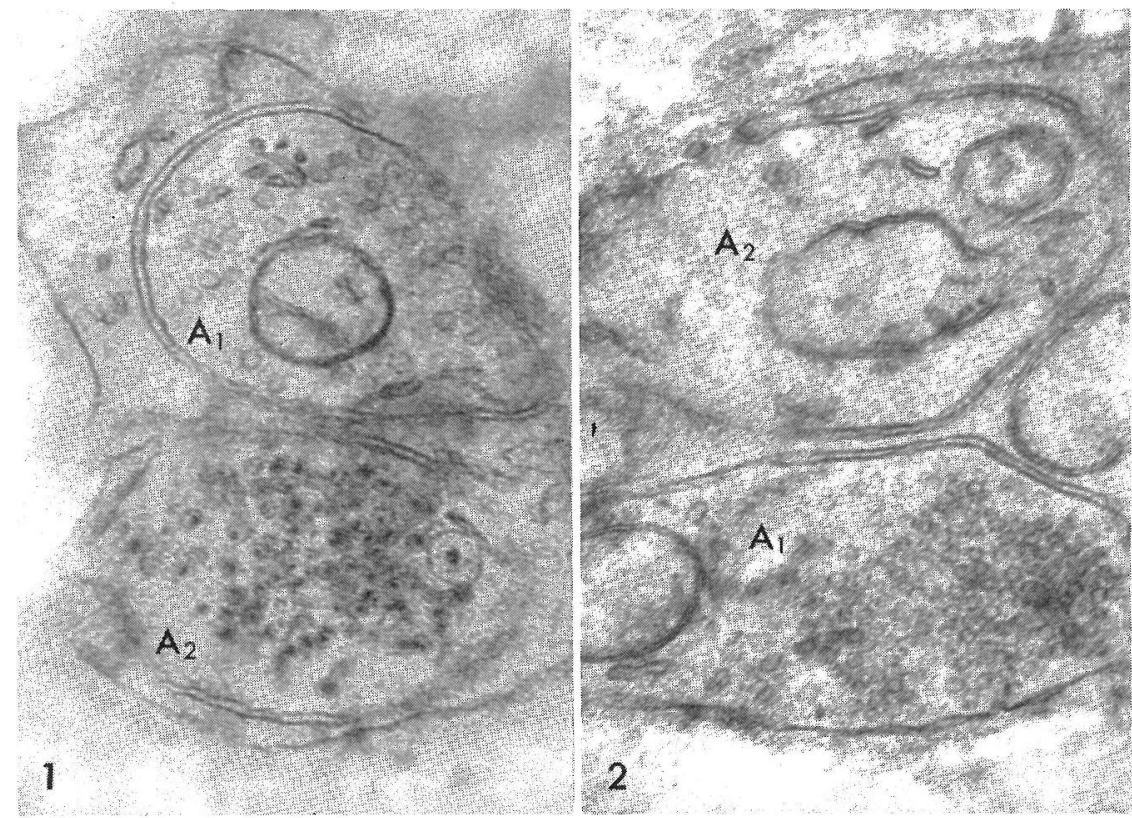

Fig. 1. Normal rabbit iris, fixed with $3 \% \mathrm{KMnO}_{4}$ in phosphate butfer $(\mathrm{pH} \mathrm{7.0)}$. Two apposed unmyelinated axons covered by a Schwann cell between the dilator layer and the sphincter zone. Note that the axon above $\left(A_{1}\right)$ has only agranular vesicles, whereas the axon below $\left(\mathrm{A}_{2}\right)$ a number of the granular vesicles. $\times 53,000$

Fig. 2. Reserpinized rabbit iris, fixed with the same fixative as in Fig. 1. Two unmyelinated axons, one with agranular vesicles $\left(A_{1}\right)$ and the other with almost no vesicles $\left(\mathrm{A}_{2}\right)$, in the stroma close to the dilator. $\times 48,000$ 

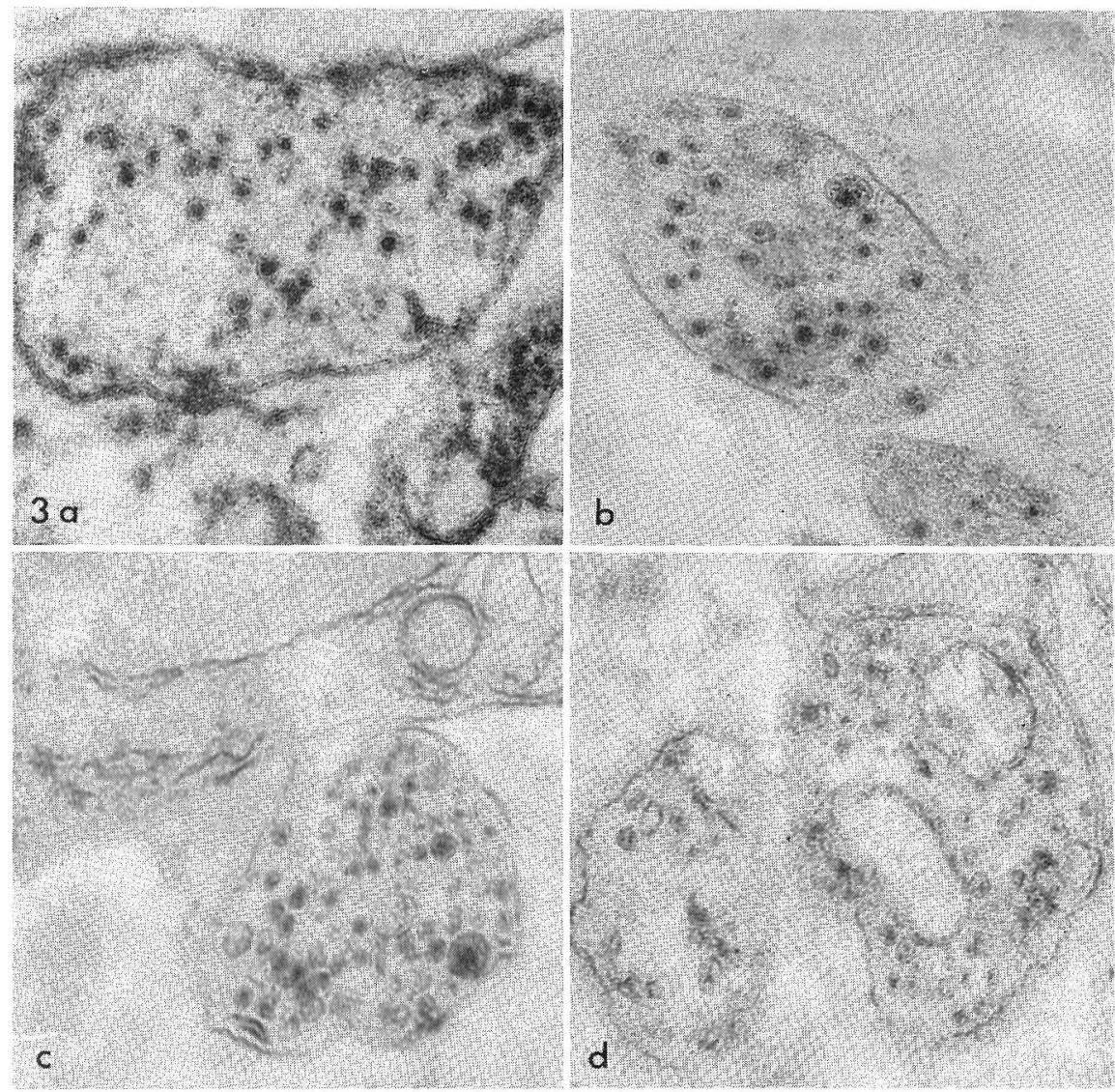

Fig. 3. Normal rabbit iris. Influence of the $\mathrm{pH}$ of $3 \% \mathrm{KMnO}_{4}$ solutions on the granular vesicles. a, $\mathrm{pH} 1.0 ; \mathrm{b}, \mathrm{pH} 5.8 ; \mathrm{c}, \mathrm{pH} 7.9 ; \mathrm{d}, \mathrm{pH}$ 10.0. Observations were made with unstained scetions. Note the more conspicuous appearance of the granules in the granular vesicles at the range of acid $\mathrm{pH} . \times 50,000, \times 57,000, \times 54,000$, and $\times 53,000$, respectively

cell, were clearly demonstrated between the iris dilator and sphincter muscles by the use of a $\mathrm{KMnO}_{4}$ fixation solution (Fig. 1). This finding offers us evidence to confirm that not all synaptic vesicles appear granular after $\mathrm{KMnO}_{4}$ fixation. It seems highly probable that these granular vesicles are the storage site for noradrenalin since the granules in the vesicles were almost completely depleted by prior administration of reserpine, a catecholamine-depleting drug (Fig. 2).

\section{The influence of the $\mathrm{pH}$ of the fixation solutions of the granular vesicles.}

The pH range tested was from 1.0 to 10.0. As is shown in Fig. 3, the lower the $\mathrm{pH}$ of the fixation solution, the more conspicuous the granules of the vesicles appear. However, the fixation quality of other tissue components was considerably poorer in cases in which the $\mathrm{pH}$ of the fixation fluid was extremely far from neutrality. 


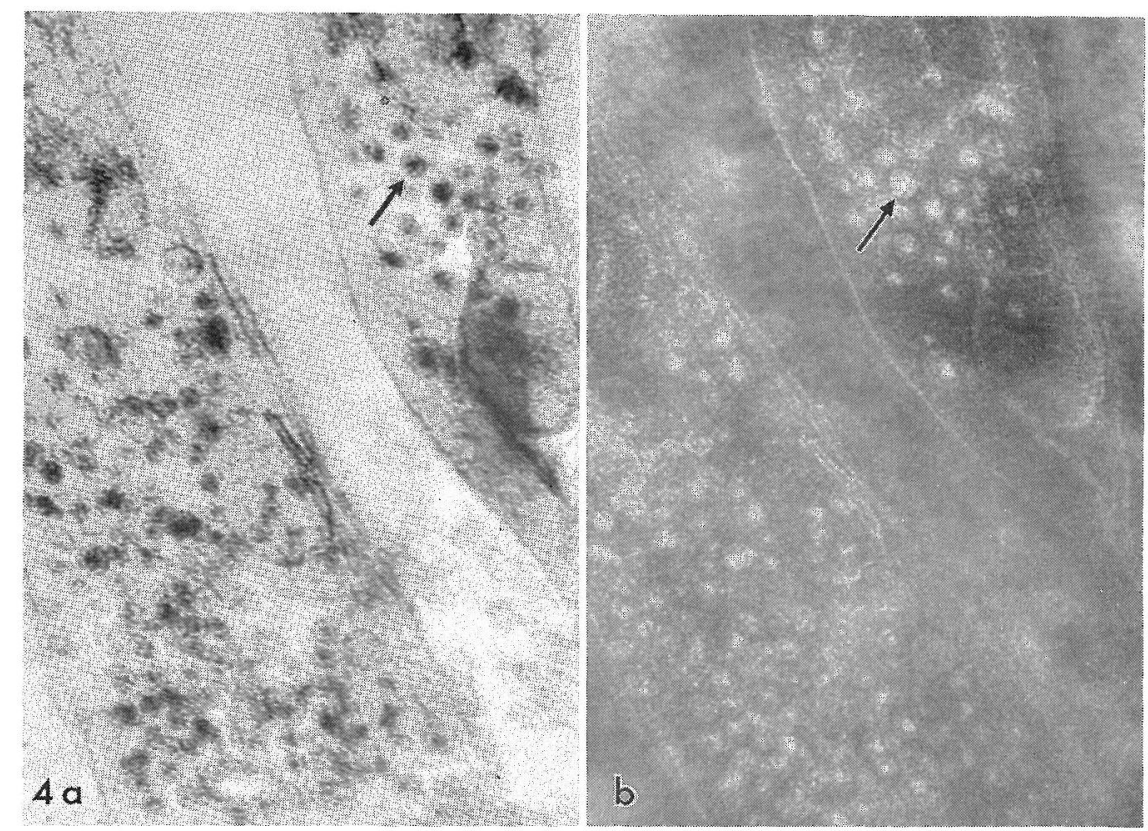

Fig. 4. Normal rabbit iris, fixed with $3 \% \mathrm{KMnO}_{4}$ in phosphate buffer ( $\mathrm{pH} 7.0$ ). Treatment of an unstained section with fuming $\mathrm{HCl}$ for $5 \mathrm{~min}$. a, before the treatment; b, after the treatment. An arrow in Fig. 4 a indicates a typical granular vesicle, and an arrow in Fig. $4 \mathrm{~b}$ the identical vesicle with that indicated in Fig. $4 \mathrm{a}$. Note the loss of high electron density of the granular vesicles after the treatment and the resulting reverse contrast similar to that obtained by negative staining. $\quad \times 54,000$

Considering these facts, a $3 \% \mathrm{KMnO}_{4}$ solution at a $\mathrm{pH}$ of ca. 6.0 is recommended for the fixation of granular vesicles.

\section{The nature of the high electron density of the granules in the granular vesicles.}

After treatment of sections with fuming hydrochloric acid, the granules in the vesicles were completely freed of highly electron dense material (Fig. 4). Treatment with other mineral acids or sodium hydroxide produced no remarkable change. This result suggests that the high electron density of the granules was caused by the precipitation of $\mathrm{MnO}_{2}$ which is soluble in fuming hydrochloric acid.

\section{Improvement of the $\mathrm{KMnO}_{4}$ fixation method for granular vesicles.}

The best fixation is obtained in materials fixed in $3 \% \mathrm{KMnO}_{4}$ in dichromate$\mathrm{KOH}$ buffer at $\mathrm{pH}$ 6.0. The granular vesicles appear more constantly with central granules, the granularity of the fixed tissue is relatively fine and membrane systems are quite satisfactorily preserved (Fig. 5). We also find that this fixation solution is superior to the other $\mathrm{KMnO}_{4}$ fixatives tested, especially for the detection of granular vesicles in tissues rich in lipids, like brown adipose tissue (Ochi et al., to be published). 


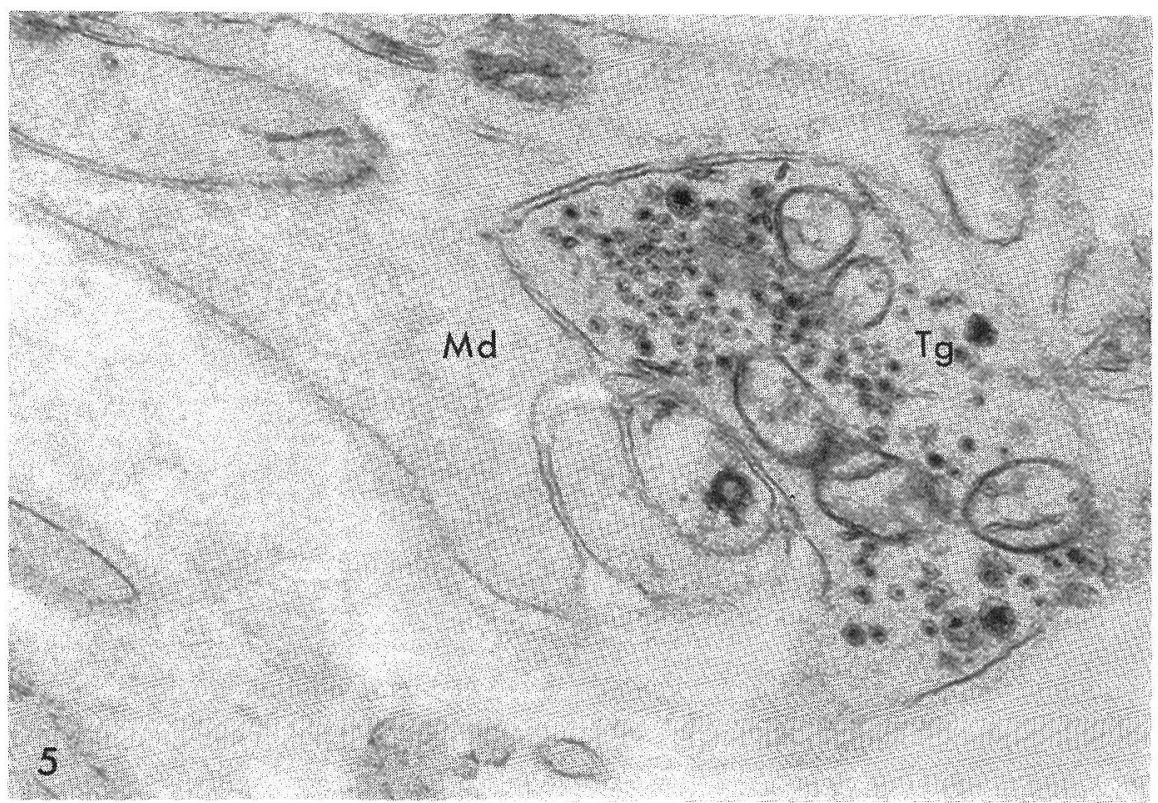

Fig. 5. Normal rabbit iris, fixed with $3 \% \mathrm{KMnO}_{4}$ in dichromate buffer ( $\mathrm{pH} \mathrm{6.0).} \mathrm{A}$ nerve terminal containing the granular vesicles $(\mathrm{Tg})$ is closely contacted with an iris dilator muscle $(\mathrm{Md})$. Note the relatively good preservation of the granular vesicles and other cell components. $\times 45,000$

\section{DISGUSSION}

The mechanism of fixation with $\mathrm{KMnO}_{4}$ for the granular vesicles in the sympathetic nervous system can be considered as follows: $\mathrm{KMnO}_{4}$, a strong oxidizing agent, presumably oxidizes noradrenaline to noradrenochrome. Noradrenochrome may escape from the vesicles (4). $\mathrm{KMnO}_{4}$ itself is reduced to $\mathrm{MnO}_{2}$ which combines with or precipitates on carrier lipo- or glycoproteins. The deposited $\mathrm{MnO}_{2}$ gives sufficient electron density to the vesicles for electron microscopy.

The experiment on sections with conc. mineral acids or alkali supports this hypothesis because $\mathrm{MnO}_{2}$ is slowly dissolved only in cold fuming hydrochloric acid, but not in nitric or sulfuric acids, nor in conc. sodium hydroxide. This was confirmed by an in vitro test. Considering the more vigorous oxidizing action of $\mathrm{KMnO}_{4}$ in acid solution than in alkali, it is easily understood that $\mathrm{KMnO}_{4}$ fixation for the granular vesicles is more effective at acid $\mathrm{pH}$.

As described in the results, the best quality of fixation for the vesicles can be obtained from a $3 \% \mathrm{KMnO}_{4}$ solution using potassium dichromate as buffer. In this case potassium dichromate probably acts not only as a buffer, but also as a fixative, especially for lipids in the tissue, as is observed in light microscopy. An increase in electron density of granules in the vesicles might be due to a reduced chromic compound of $\mathrm{K}_{2} \mathrm{Cr}_{2} \mathrm{O}_{7}$ precipitated on the granules, in addition to $\mathrm{MnO}_{2}$. This consideration is based on the fact that chrome or a chromic compound resulting from the chromaffin reaction gives a high electron density to catecholamine- 
containing granules in electron microscopy (1).

\section{AGKNOWLEDGMENT}

The author's thanks are due to Prof. Y. Sano for his interest in this work and for his kind criticism of this manuscript.

Note added in proof: Since this paper was received for publication, a paper by Hökfelt and Jonsson (Histochemie $16 ; 45,1968$ ) has come to the author's attention. Independently of this study, they also consider that during the fixation with $\mathrm{KMnO}_{4}$ noradrenaline reduces probably $\mathrm{KMnO}_{4}$ to $\mathrm{MnO}_{2}$, which is the main constituent of the precipitate on the cores in the small granular vesicles.

\section{REFERENGES}

1. Arnold, M. und Hagar, G.: Zum Kontrast von Gatecholamingranula im Elektronenmikroskop. Histochmie 14; 297, 1968.

2. Bloom, F. E. and Barrnett, R. J.: Fine structural localization of noradrenaline in vesicles of autonomic nerve endings. Nature (Lond.) 210; 599, 1966.

3. De Robertis, E. and Pellegrino de Iraldi, A. : A plurivesicular component in adrenergic nerve endings. Anat. Rec. 139; 299, 1961.

4. Devine, C.E. and Laverty, R.: Fixation for electron microscopy and the retention of ${ }^{3} \mathrm{H}$-noradrenaline by tissues. Experienntia (Basel) 24; 1156, 1968.

5. Devine, G. E. and Simpson, F. O.: The fine structure of vascular sympathetic neuromuscular contact in the rabbit. Anat. Rec. 121; 153, 1967.

6. Grillo, M. and Palay, S. L.: Granule-containing vesicles in the automonic nervous system. In Electron Microscopy, vol, 2. U-1, edited by S. S. Breese jr., Academic Press, Inc., New York, 1963.

7. Hökfelt, T. : On the ultrastructural localization of noradrenaline in the central nervous systme of the rat. Z. Zellforsch 79; 110, 1967.

8. Machado, A. B. M. : Straight $\mathrm{OsO}_{4}$ versus glutaraldehyde-OsO $\mathrm{O}_{4}$ in sequence as fixatives for the granular vesicles of sympathetic axons of the rat pineal body. Stain Technol. 42; 293, 1967.

9. Ochi, J., Konishi, M., Yoshikawa, H. and Sano, Y. : Fluorescence and electron microscopic evidence for the dual innervation of the iris sphincter muscle of the rabbit. Z. Zellforsch. 91; 90. 1968.

10. Richardson, K. G.: Electron microscopic identification of autonomic nerve endings. Nature (Lond.) 210; 756, 1966.

11. Wolfe, D. E., Potter, L. T., Richardson, K. C. and Axelrod, K.: Localizing tritiated norepinephrine in sympathetic axons by electron microscopy and autoradiography. Science 138; 440, 1962.

12. Wood, J. D. and Barrnett, R. J.: Histochemical demonstration of norepinephrine at a fine structural level. J. Histochem. Cytochem. 12; 197, 1964. 